Acta Universitatis Wratislaviensis

No 3726

Anglica Wratislaviensia LIV

Wrocław 2016

DOI: $10.19195 / 0301-7966.54 .4$

Ilka Floeck

Joanna Pfingsthorn

Carl von Ossietzky University of Oldenburg

\title{
Comparing Instrument-induced Effects in EFL Requests: Task-based Approach versus Discourse Completion Task
}

\begin{abstract}
In Interlanguage Pragmatics (ILP) research, the Discourse Completion Task (DCT) is the main source of insight into speakers' productions of pragmatic phenomena. Its omnipresence as a means of data collection can be explained by the need of comparability of data sets and (sociolinguistic) variable control. However, some studies suggest a discrepancy between surface realisations observed in naturally occurring data and experimental data like DCTs (cf. e.g. Beebe and Cummings 1996; Golato 2003).Unfortunately, the results of these studies are inconclusive and do not offer any information about quantitative differences in realisation patterns and about the impact of different methodological approaches on interlanguage data.

It is therefore the aim of the present study to compare the influence of two methods of data collection, DCTs and task-based elicited conversations, on the realisation of the head act strategies in requests produced by advanced learners of English. Overall, our results show a significant difference in the distributions of request head act strategies across the two methodological conditions. The conversational head acts are substantially more direct than the requests elicited by DCTs. The patterns observed in learner data strongly resemble the ones found in native speaker requests in the same methodological scenarios. This implies that despite earlier claims, advanced learners can display target-like language use. The resemblances furthermore indicate that semi-naturalistic methods of data collection are a more valid means to obtain learner data that is representative of naturally occurring conversations.
\end{abstract}

Keywords: interlanguage pragmatics, discourse completion task, task-based elicited conversations, head acts strategies, requests, semi-naturalistic methods, data collection

\section{Introduction}

Despite Bardovi-Harlig (1999) calling for the inclusion of more diversified naturalistic data collection instruments in the study of interlanguage discourse, studies on the production of learner speech acts still rely heavily on experimental data, such 
as the Discourse Completion Test (DCT). The prevalence of such instruments of data collection is problematic as methodological comparisons have revealed differences between naturally occurring and DCT-based speech acts. While the use of what Jucker calls laboratory methods (cf. Jucker 2009) in interlanguage pragmatic research is understandable from a practical perspective (high control of speaker, linguistic and test variables), it is regrettable from a theoretical point of view. Almost all our knowledge about learners' pragmatic competence stems from experimentally elicited language data which may not represent naturally occurring speech acts validly. Yet, the effects that such instruments have on the language produced are still not fully understood. While there is some research on instrument-effects in native speaker populations (and even that provides us with inconclusive results), there are hardly any studies to date which investigate such effects on learner populations.

The present paper aims at filling this research gap by comparing the influence of two different instruments of data collection on a specific pragmatic variable, the speech act of requests. More specifically, our analysis focuses on the distribution of head act directness levels in data elicited by DCTs and observed in task-based interactions.

We will first briefly define the linguistic variable under investigation in Section 2.1. before critically discussing existing research on instrument-effects on pragmatic phenomena in Section 2.2. In Section 2.3. we will introduce the notion of tasks before discussing our task-based research design and the database in Section 3. In Section 4 we will present and discuss our results and come to a conclusion in Section 5.

\section{Theory}

\subsection{Requests in interlanguage and cross-cultural pragmatics}

Requests are a subclass of directive speech acts which have been very broadly defined as "attempts (of varying degree ...) by the speaker to get the hearer to do something" (Searle 1976: 13). Their function can be further defined in terms of felicity conditions as outlined in Searle (1969) (cf. Table 1).

Table 1. Felicity conditions for directive speech acts

\begin{tabular}{|l|l|}
\hline \multicolumn{1}{|c|}{ Condition } & \multicolumn{1}{c|}{ Directive speech acts } \\
\hline Essential & $\begin{array}{l}\text { Counts as an attempt by a speaker (S) to get a hearer (H) to do a future } \\
\text { action (x). }\end{array}$ \\
\hline Sincerity & S wants H to do x. \\
\hline Preparatory & $\begin{array}{l}\text { (a) } \mathrm{H} \text { is able to perform } \mathrm{x} \text {. S believes } \mathrm{H} \text { is able to do } \mathrm{x} . \\
\text { (b) It is not obvious that } \mathrm{H} \text { would do } \mathrm{x} \text { without being asked. }\end{array}$ \\
\hline Propositional content & Counts as an attempt by $\mathrm{S}$ to get $\mathrm{H}$ to do a future action. \\
\hline
\end{tabular}


From a politeness perspective, requests have been described as intrinsically threatening the hearer's negative face since the speaker imposes on the hearer's freedom of will (cf. Brown and Levinson 1987: 66). They often do not occur in the most direct and unambiguous form (i.e. the imperative) but are modified by various linguistic means. This can be achieved by employing head acts of different directness levels and internal and external modification (Blum-Kulka, House, and Kasper 1989a). Head acts are defined as "the minimal unit which can realize a request" (Blum-Kulka, House, \& Kasper 1989c: 275). Employing conventionally indirect and direct head acts can therefore be understood as negative politeness strategies in Brown \& Levinson's terms in that they linguistically signal that the hearer has the choice of not complying with the directive speech act. Modifiers serve the function of minimising the imposition on the hearer or lessen the negative effect of the directive speech act.

Empirical investigations of requests in cross-cultural and interlanguage pragmatics research have made use of mainly DCTs and role-plays as means of data collection (cf. e.g. Barron 2008; Blum-Kulka 1982; Blum-Kulka et al. 1989b; Breuer and Geluykens 2007; Cohen and Olshtain 1993; Faerch and Kasper 1989; House and Kasper 1981; Trosborg 1994). While there are some exceptions to this rule for other languages (cf. e.g. Achiba 2003; Placencia 1998), there is a regrettable lack of such studies for the English language. Investigations of requests with DCTs in different native speaker and learner varieties of English have reported that, despite some cross-cultural and situational variation, the most frequently employed strategy in all groups is the query preparatory (cf. Flöck and Geluykens 2015; Flöck shoud be for an overview). In this strategy, the speaker makes conventionalised reference to the preparatory condition of a request (Hey, could I borrow your lecture notes?). Preparatory queries and other conventionally indirect strategies account for the vast majority of request realisations in DCT-based studies (on average more than $80 \%$ of all head acts).

Most studies concerned with comparisons of native speaker and learner speech acts and other pragmatic phenomena report that even advanced learners of English struggle with target-like output (for an overview, cf. Kasper and Rose 2002). However, a significant portion of the understanding of learners' use of requests derives from experimental data (role-plays, DCTs and DCT-derived questionnaire formats such as cartoon production tasks shoud be (Rose 2005) or multi-media elicitation tools).

\subsection{Influence of methodology on the production of speech acts}

The literature on instruments of data collection in pragmatics is rich with assumptions and empirical evidence that instruments of data collection can influence or even shape the data they elicit or observe. Because of their omnipresence in ILP research, DCTs have attracted much and vehement criticism from a substantial 
number of researchers. DCTs provide the informant with a situational description in which the fictitious situation is explained and (optionally) a cue is given for what kind of illocution the informant is to produce as a response. Thus, they are simulations of language use on two dimensions: participants who not only have to imagine fictitious scenarios in which they use language, but they also have to pretend to use spoken language while they are actually delivering responses in writing.

Researchers have reported that DCTs might not elicit data that are representative of naturally occurring discourse or data produced in other methodological conditions for almost as long as the tool has been in use (cf. Rintell and Mitchell 1989). As early as 1991, Kasper and Dahl (1991: 215) warn that researchers in pragmatics are faced with "a double layer of variability" and draw attention to the fact that researchers should be aware of the influence which various independent variables (social or instrument-based ones) simultaneously exert over the dependent variable under investigation. Despite such warnings and reports, the DCT soon developed into the most popular instrument of data collection for a number of reasons: (1) It allows researchers to collect large samples of data, (2) it allows for high variable control (which is highly important in research), (3) it enables researchers to manipulate sociopragmatic and macro-social variables systematically, and (4) it is relatively easy to administer.

While many authors have voiced their general scepticism about the validity of DCTs, systematic research on the kind of instrument effects exerted is rare and the results are inconclusive (cf. Flöck 2016) for a comprehensive overview). Based on her comparison of naturally occurring and DCT-elicited compliment responses in German, Golato (2003) claims that only naturally occurring data can yield valid results about patterns of speech act realisation. She finds that DCTs over-represent on salient strategies and produce speech acts that are longer yet more routinized than naturally occurring speech acts. She further reports that DCT informants comment on the unnaturalness of the task. In line with Golato's conclusions, Flöck 2016 finds statistically significant differences between conversational requests and requests elicited by DCTs. She reports that the conversational requests are much more direct on the head act level and include fewer mitigators than the DCT ones. Similar to Golato, the author concludes that DCTs do not represent language use reliably and should thus be replaced as an instrument of data collection. In her comparison of DCT and naturally occurring requests, Economidou-Kogetsidis (2013) also finds significant differences across methodological conditions but diverges drastically from Golato's (2003) and Flöck's (2016) results and conclusions. Economidou-Kogetsidis' (2013) analysis of head act strategies and internal modification reveals that requests elicited through DCTs are significantly more direct than the ones found in telephone conversations. The numbers of internal modifiers (with mitigating function) are higher in the naturally occurring data set and are thus in line with the findings about head act 
realisations. As Economidou-Kogetsidis (2013) includes different request types (for verbal and non-verbal action) in both of her data sets, it is doubtful whether the directness differences between her DCT and naturally occurring data can be attributed to the methodological difference. In contrast to the author's claims, they are more likely to be artefacts of the different nature of the requests included in the analysis. In their comparison of formulaic expressions of gratitude, Schauer and Adolphs (2006) also report on significant differences between DCT and naturally occurring speech acts. They find that DCTs frequently produce strategies for expressing gratitude which are not found in the naturally occurring data sets at all. The authors explain this finding by the fact that "participants in the DCTs had more time to think about their response and have therefore opted to produce an additional politeness strategy" (Schauer \& Adolphs 2006: 129). On more general grounds, the authors argue that naturally occurring discourse requires faster processing of information and speech, which in turn explains the repetitive usage of gratitude formulae in naturally occurring speech acts (cf. Schauer \& Adolphs 2006: 129). The authors also find (similar to Golato 2003) that production questionnaires are unable to capture discursive phenomena such as repeated patterns of collaborative negotiation of expressions of gratitude and thus conclude that DCTs "can never provide the same variety of discourse contexts as the corpus" (Schauer \& Adolphs 2006: 131).

The last two studies comparing naturally occurring data to DCTs are similar in that they investigate speech acts which typically occur as second pair parts but provide ambiguous findings. While Hartford and Bardovi-Harlig (1992) find that DCTs elicit a smaller range of rejection strategies and furthermore do not elicit strategies which are frequently used in the naturally occurring discourse, Beebe and Cummings (1996) report that their DCT data contain the same number of strategies (or what they call "semantic formulae"). Whereas the studies come to different conclusions about the range of formulae used, they generally find very similar differences between DCTs and naturally occurring data in other analytical categories. Beebe \& Cummings (1996) find that DCT responses contain fewer words, sentences, elaborations, hedges and negotiation strategies. Hartford \& Bardovi-Harlig (1992) further find that DCTs are more direct, exhibit fewer status preserving strategies and generally are unable to capture the sequential organisation and interactional character of rejections. The authors assume that the differences between DCTs and naturally occurring data are possibly caused by participants' lack of exposure to some situations in the DCT and warn that production questionnaires are likely to have a "forcing effect" (Hartford and Bardovi-Harlig 1992: 50) that does not occur in the naturally occurring situations.

To summarise, the studies comparing naturally occurring data to data elicited through DCTs show instrument effects on the levels of sequential organization, modifier use, utterance length, directness preferences, and the range of semantic formulae employed. Given the design of DCTs, it is not surprising that there 
seems to be unanimous agreement that the tool at the very least cannot capture patterns of sequential organisation, interactional phenomena and negotiation strategies typical of naturally occurring spoken discourse. Although there is competing evidence for some phenomena, past research generally seems to agree that DCTs cannot elicit language use which is fully or even partially representative of naturally occurring discourse. While the validity of DCT data has been contested based on the analysis of native speaker data, we set out to investigate whether similar instrument-induced effects can also be found in advanced EFL learner requests.

\subsection{Task-based elicitation of conversations}

Ellis (1994: 671) suggests that natural language data result from learners trying to "use their L2 knowledge in communication." However, for many non-native speakers of English or students in EFL classrooms the need to use English as a lingua franca may simply never arise naturally. While this lower frequency of natural communication among EFL students does not diminish the necessity to study their language production, it certainly increases the need to find data collection methods that simulate natural language use.

In recent years, the notion of a task has become an important element of classroom teaching. Ellis (2003: 16) defines a pedagogical task in the following way:

A task is a workplan that requires learners to process language pragmatically in order to achieve an outcome that can be evaluated in terms of whether the correct or appropriate propositional content has been conveyed. To this end, it requires them to give primary attention to meaning and to make use of their own linguistic resources, although the design of the task may predispose them to choose particular forms. A task is intended to result in language use that bears a resemblance, direct or indirect, to the way language is used in the real world. Like other language activities, a task can engage productive or receptive, and oral or written skills and also various cognitive processes.

Task-based instruction is generally perceived to foster various modern teaching principles and practices such as needs-based content selection, learning to communicate through real interaction, the use of authentic materials in learning situations, opening opportunities for learners to focus on the learning process and its connection with the learner's personal experiences as well as language use outside the classroom (Ellis 2003). Although some scholars claim that systematic teaching of new linguistic material may be difficult in the task-based framework and that it needs integration with form-based approaches (Swan 2005), there is little doubt that task-based instruction requires learners to attain a certain objective and thereby shifts their attention away from form onto meaning, which in turn decreases the likelihood of creating situations with no authentic communicative intent. It therefore stands to reason that applying a task-based design to collecting learner data might be as beneficial for research purposes as it is for language 
teaching. We assume that using tasks as a means of data collection can provide researchers interested in L2 production with a more naturalistic, yet practical and feasible, approach to data collection that reduces the observer's bias. In the present paper, we would like to empirically test whether a task-based research design is valid in that it produces language use comparable to naturally occurring data.

\section{Methodology}

\subsection{Data collection}

The methodological comparison attempted in the study at hand requires at least two different but maximally comparable data sets. For the conversational data, transcripts of video recorded elicited conversations of task-based interactions between three non-native speakers of English per group were used. Informants received the instruction to build a tower out of a given set of materials and converse as freely as possible in their interlanguage English. The conversational data used for the present analysis were extracted from two interactions of about 30 minutes each. The questionnaire data were elicited with the help of the three equal power request scenarios created for the Cross-cultural Speech Act Realisation Project (notes, kitchen, ride; cf. Blum-Kulka et al. 1989b).

Both data sets are maximally comparable in terms of language proficiency of the informants (all speakers scored at least 100 points in the internet based TOEFL test or equivalent tests), their L1 (German) and their demographic background in term of gender and age. The head acts in the conversational data set were obtained in manual searches of the transcripts in a conversation analytic approach (cf. Jucker 2009).

Since the present paper focuses on the use of requests of non-native speakers of English in an EFL context, the use of elicited conversations (in contrast to naturally occurring conversations) was unavoidable. Since all informants share the same L1, they do not use their interlanguage naturally in everyday situations. The taskbased design was specifically chosen to distract informants from the recording situation in order to increase authenticity of the data and lower the influence of the observer's paradox (cf. Labov 1972).

To be able to establish whether the learner database displays the same similarities or differences across methodological conditions as have been described for native speaker populations (cf. Section 2.2), two native speaker control groups are included in the present analysis. They consist of a sample of naturally occurring conversational requests retrieved from the British component of the International Corpus of English (ICE) and requests elicited from British English (BrE) native speakers through DCTs. The current studies thus draws on four data sets as displayed in Figure 1. 


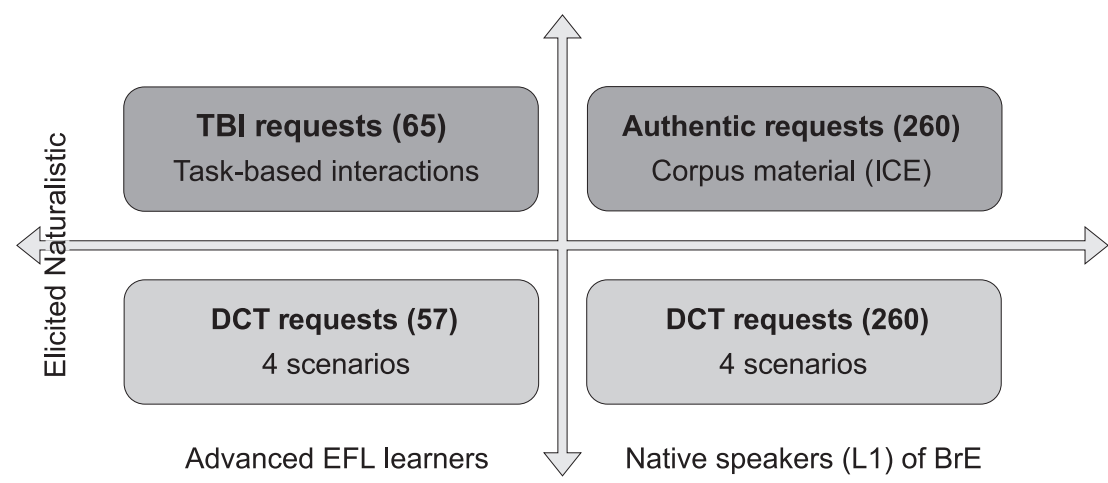

Figure 1. Data sets analysed in the current study

\subsection{Coding and statistics}

To enable comparability between the data sets used for the present analysis and with other studies working on requests, the widely-used coding scheme by BlumKulka et al. (1989b) was employed. The coding scheme differentiates between the head act which is defined as "the minimal unit which can realize a request" (Blum-Kulka et al. 1989c: 275) and different linguistic means of internal and external modification which function to either mitigate or aggravate the force of the speech act. The present analysis focuses on the realisation of head acts only. On the head act level, we distinguish between mostly structurally defined strategies which pattern into three directness levels (cf. Table 2). The directness levels were empirically established in Blum-Kulka (1987) who had native speakers of English rate a number of request strategies according to their directness level.

Table 2. Request strategies (cf. Blum-Kulka 1987; examples from the TBI database)

\begin{tabular}{|l|l|l|}
\hline \multicolumn{1}{|c|}{ Directness level } & \multicolumn{1}{|c|}{ Strategy } & \multicolumn{1}{c|}{ Example } \\
\hline I & Mood derivable & Give me the red glue please. \\
\hline & Locution derivable & I need one more. \\
\hline II & Suggestory formula & Let's add a green one for color. \\
\hline & Preparatory & Can you help me take this one off? \\
\hline III & Hint & Where's the glue? \\
\hline
\end{tabular}

\section{Results and discussion}

The requests elicited in DCTs and found in the conversational data set differ both qualitatively and in their frequency distribution. In line with Hartford and Bardovi-Harlig's (1992) findings, the conversational data produced a greater 
variety of head act strategies than the DCTs. While an overall number of six strategies was found in the conversations, the DCTs only elicited three head act strategies.

The distribution of head act strategies and directness levels in the two methodological conditions shows that learner requests are significantly more direct in the task-based data set compared to DCT requests (cf. Figure 2). While the majority of all requests fall in the most direct head act levels in the task-based interactions $(69 \%)$, they only account for $5 \%$ in the DCT database. The opposite trend can be observed for requests in the intermediate directness level. The DCT database consists almost exclusively of requests of this type (91\%) whereas directness-level II requests only account for less than a third of all task-based interaction requests. Not surprisingly, the differences in directness levels across the methodological conditions are statistically significant at the $\mathrm{p}<0.001$ level $\left(\chi^{2}(1)=52.071, \mathrm{p}<\right.$ 0.001 ) with a large effect size (Cramer's $\mathrm{V}=0.653$ ).

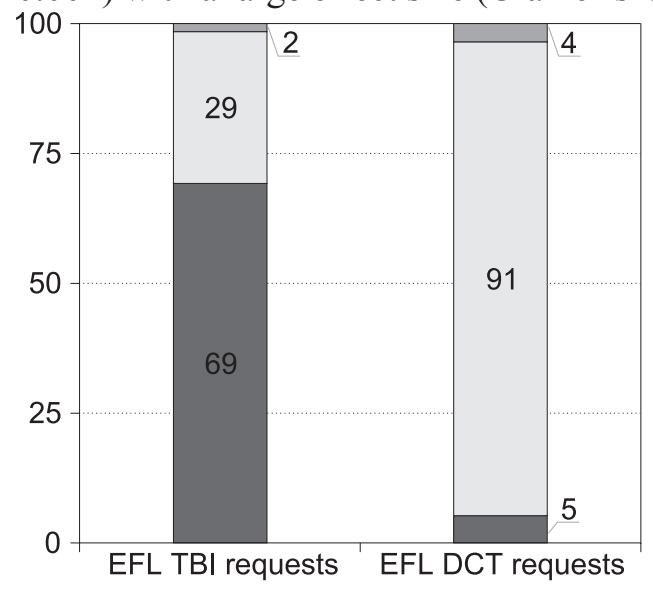

$\square$ Directness level I $\square$ Directness level II $\square$ Directness level III

Figure 2. Request directness levels in the learner task-based interaction and DCT data

The analysis of requestive head act strategies thus reveals a highly significant effect of the instrument of data collection on the directness levels of the speech acts produced. At this stage, however, the question remains of how the task-based interactional requests compare to requests collected in truly non-elicited (i.e. naturally occurring) requests. For this purpose, the directness levels of the task-based EFL requests analysed for the present study were compared to naturally occurring British English native speaker requests. The distribution of directness levels (as displayed in the two left-hand columns in Figure 3) shows more similarities than differences between task-based EFL requests and BrE native speaker conversational requests.

While the task-based interactional learner requests seem to be slightly more direct than the native speaker requests, the differences are not statistically 
significant $\left(\chi^{2}(1)=4.665, p>0.1\right)$. Despite claims in the literature that even advanced learners still struggle with target-like production of pragmatic phenomena, the requests of the advanced EFL learners sampled for the present study closely resemble native speaker directness patterns. A similar trend is also observable when comparing our advanced EFL learner DCT requests to BrE native speaker DCT requests. There are virtually no differences in directness level usage across the two groups (as displayed in the two right-hand columns in Figure 3). Given the minimal differences, it is not surprising that the differences are not statistically significant $\left(\chi^{2}(1)=0.239, p>0.4\right)$.

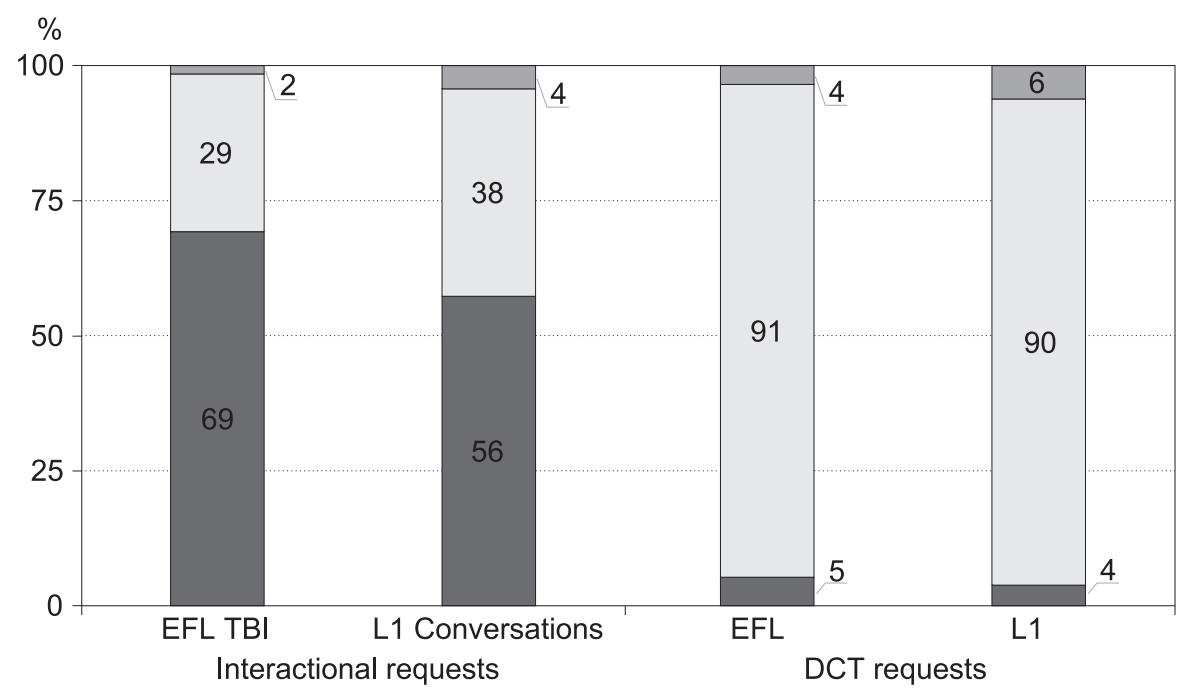

Figure 3. Directness levels in the task-based learner and naturally occurring BrE requests

Whereas the differences between learner and native speaker requests are not statistically significant in either instrument condition, the differences between interactional requests and DCT-based requests are considerable. The distribution of request directness levels in both learner and native speaker output across instrument conditions thus supports earlier claims that language production found in questionnaires and conversational data diverges. It is therefore highly questionable whether DCTs can be a valid measure of speech act behaviour and competence.

\section{Conclusion}

The results of the present study support Bardovi-Harlig's (1999) call for the inclusion of a more varied set of methods in interlanguage pragmatics both on a theoretical and applied dimension. Finding a valid measure of learner competence 
requires the implementation of various data collection methods that go beyond questionnaire data. As linguistic research and pedagogical applications should go hand in hand, the inclusion of such methods could lead to the development of more representative teaching materials and forms of language assessment.

A hybrid approach to data collection such as task-based elicited conversation (as employed in the present study) seems to deliver results comparable to those obtained from naturally occurring data while at the same time allowing researchers the same control over variables which DCTs and DCT-derived methods such as role-plays offer. We therefore encourage the use of such semi-naturalistic data in future research. As the present study lends further support of Ellis' (1994) claim that task-based learning promotes the production of authentic language use, we also encourage the use of task-based designs in the EFL classroom.

Despite the fact that the data sets used for the present study are limited in size and would need to be expanded to gain more representative insights, they still closely resemble the results obtained from analyses of larger data samples (BrE corpus data and DCTs). This is a clear indicator that similar patterns can be expected once the database has been extended.

\section{References}

Achiba, M. 2003. Learning to Request in a Second Language. A Study of Child Interlanguage Pragmatics. Clevedon: Multilingual Matters.

Bardovi-Harlig, K. 1999. "Exploring the interlanguage of interlanguage pragmatics: A research agenda for acquisitional pragmatics." Language Learning 49.4. 677-713.

Barron, A. 2008. "The Structure of Requests in Irish English and English English." In: Schneinder, K.P. and A. Barron (eds.) Variational Pragmatics: A Focus on Regional Varieties of Pluricentric Languages. Amsterdam and Philadelphia: Benjamins, 35-67.

Beebe, L.M. and M.C. Cummings. 1996. "Natural Speech Act Data versus Written Questionnaire Data: How Data Collection Method Affects Speech Act Performance." In: Gass, S.M. and J. Neu (eds.) Speech Acts across Cultures: Challenges to Communication in a Second Language. Berlin and New York: Mouton de Gruyter, 65-86.

Blum-Kulka, S. 1982. "Learning to say what you mean in a second language." Applied Linguistics 3.1. 29-59.

Blum-Kulka, S. 1987. “Indirectness and politeness in requests: Same or different?" Journal of Pragmatics 11.2. 131-146.

Blum-Kulka, S., J. House and G. Kasper. 1989a. Cross-Cultural Pragmatics: Requests and Apologies. Norwood, NJ: Ablex.

Blum-Kulka, S., J. House and G. Kasper. 1989b. "Investigating Cross-Cultural Pragmatics: An Introductory Overview.” In: Blum-Kulka, S., J. House and G. Kasper (eds.) Cross-Cultural Pragmatics: Requests and Apologies. Norwood, NJ: Ablex, 1-34.

Blum-Kulka, S., J. House and G. Kasper. 1989c. "The CCSARP Coding Manual." In: BlumKulka, S., J. House and G. Kasper (eds.) Cross-Cultural Pragmatics: Requests and Apologies. Norwood, NJ, USA: Ablex, 273-294. 
Breuer, A. and R. Geluykens. 2007. "Variation in British and American English Requests. A Contrastive Analysis." In: Kraft, B. and R. Geluykens (eds.) Cross-Cultural Pragmatics and Interlanguage Pragmatics. München: Lincom Europa, 107-126.

Brown, P. and S.C. Levinson. 1987. Politeness. Some Universals in Language Usage. Cambridge: Cambridge University Press.

Cohen, A.D. and E. Olshtain. 1993. "The production of speech acts by EFL learners." TESOL Quarterly 27.1. 33-56.

Economidou-Kogetsidis, M. 2013. "Strategies, modification and perspective in native speakers' requests: A comparison of WDCT and naturally occurring requests." Journal of Pragmatics 53. 21-38.

Ellis, R. 1994. The Study of Second Language Acquisition. Oxford: Oxford University Press.

Ellis, R. 2003. Task-Based Language Learning and Teaching. Oxford: Oxford University Press.

Faerch, C. and G. Kasper. 1989. "Internal and External Modification in Interlanguage Request Realization.” In: Blum-Kulka, S., J. House and G. Kasper (eds.) Cross-Cultural Pragmatics: Requests and Apologies. New Jersey: Ablex, 221-247.

Flöck, I. 2016. Requests in American and British English: A Contrastive, Multi-Method Analysis. Amsterdam, Philadelphia: Benjamins.

Flöck, I. and R. Geluykens. 2015. "Speech Acts in Corpus Pragmatics: A Quantitative Contrastive Study of Directives in Spontaneous and Elicited Discourse.” In: Romero-Trillo, J. (ed.) Yearbook of Corpus Linguistics and Pragmatics 2015. 3. Cham: Springer International Publishing, $7-37$.

Golato, A. 2003. "Studying compliment responses: A comparison of DCTs and recordings of naturally occurring talk." Applied Linguistics 24.1. 90-121.

Hartford, B.S. and K. Bardovi-Harlig. 1992. "Experimental and Observational Data in the Study of Interlanguage Pragmatics.” In: Bouton, L.F. and Y. Kachru (eds.) Pragmatics and Language Learning. 3. Urbana, IL: University of Illinois at Urbana-Champaign, 33-52.

House, J. and G. Kasper. 1981. "Politeness Markers in English and German." In: Coulmas, F. (ed.) Conversational Routine: Explorations in Standardized Communication Situations and Prepatterned Speech. The Hague: Mouton, 157-185.

Jucker, A.H. 2009. "Speech act research between armchair, field and laboratory: The case of compliments." Journal of Pragmatics 41.8. 1611-1635.

Kasper, G. and M. Dahl. 1991. "Research methods in interlanguage pragmatics." Studies in Second Language Acquisition 13. 215-247.

Kasper, G. and K.R. Rose. 2002. "Pragmatic development in a second language. A supplement to language learning." Language Learning 52.

Labov, W. 1972. Sociolinguistic Patterns. Philadelphia: Pennsylvania University Press.

Placencia, M.E. 1998. "Pragmatic variation: Ecuadorian Spanish vs. Peninsular Spanish." Spanish Applied Linguistics 2. 71-106.

Rintell, E.M. and C.J. Mitchell. 1989. "Studying Requests and Apologies. An Inquiry into Method." In: Blum-Kulka, S., J. House and G. Kasper (eds.) Cross-Cultural Pragmatics: Requests and Apologies. Norwood, NJ: Ablex, 248-272.

Rose, K.R. 2005. "On the effects of instruction in second language pragmatics." System 33.3. 385399.

Schauer, G.A. 2007. "Finding the right words in the study abroad context: The development of German learners' use of external modifiers in English." Intercultural Pragmatics 4.2. 193-220.

Schauer, G.A. and S. Adolphs. 2006. "Expressions of gratitude in corpus and DCT data: Vocabulary, formulaic sequences, and pedagogy." System 34. 119-134.

Searle, J.R. 1969. Speech Acts: An Essay in the Philosophy of Language. Cambridge: Cambridge University Press. 
Searle, J.R. 1976. "A classification of illocutionary acts.” Language in Society 5.1. 1-23.

Swan, M. 2005. "Legislation by hypothesis: The case of task-based instruction." Applied Linguistics 26. 376-401.

Trosborg, A. 1994. Interlanguage Pragmatics: Requests, Complaints, and Apologies. Berlin and New York: Mouton de Gruyter. 